\title{
Knowledge and Attitudes of Jordanian Dentists toward Speech Language Pathology
}

\author{
Hana Nawaf Mahmoud \\ Department of Hearing and Speech Sciences, School of Rehabilitation Sciences, the University of Jordan, Amman, \\ Jordan
}

\author{
Abdelhameed N. Mahmoud \\ The University of Jordan, Amman, Jordan; \\ Jasmine Dental Implant Center, Amman, Jordan
}

\begin{abstract}
This study was conducted to assess dentists' knowledge of normal speech-language development (NSLD), speech-language disorders (SLD), and speech-language pathology (SLPy) and to determine their general attitudes toward speech-language pathology (SLPy). A self-administered, web-based questionnaire was emailed to all members of the Jordanian Dental Association Council. 191 completed questionnaire were entered in excel sheet and statistically analyzed with IBM SPSS version 20 software. The respondents demonstrated insufficient knowledge regarding normal speech-language development and speech-language disorders. Additionally, the majority of respondents reported a general impression that the speech-language pathologist has an important role in a health profession team $(\mathbf{8 6 . 8 \%})$. However, they did poorly on the normal speech-language development questions $(\mathbf{2 6 \%})$ as well as the speech-language disorders questions $(\mathbf{1 8 \%})$. There were no statistically significant differences between different variables - age, gender, years of practice, place of practice and specialty of dentists and dentists' knowledge of speech-language pathology.
\end{abstract}

Index Terms - attitudes, normal speech-language development, speech- language disorders, speech-language pathologist

\section{INTRODUCTION}

The ability to communicate is very important; it is sometimes compared to the ability to breathe (Van Hattum, 1985b). People usually communicate to share ideas and feelings that convey messages between persons or groups (McLaughlin, 2007). Communication disorders are defined by the American Hearing and Speech Association (ASHA), which is considered the largest speech and language pathology professional association worldwide, as "an impairment in the ability to receive, send, process and comprehend concepts or verbal, nonverbal and graphic symbol systems" (ASHA, 2017).

The World Health Organization (WHO) documented that $15 \%$ of the world's population is disabled, and hundreds of thousands of children suffer from disability in communication due to impairment (WHO, 2017). Speech and language disorders (SLD) are considered a major public health problem because they cause many complications from childhood to adulthood (Vameghi, Bakhtari, Shirinbayan and Hatamizadeh, 2015). Various studies in different countries have documented the prevalence rates of SLD in children in different age group to be between $3.2 \%$ and $26 \%$ (Beitchman, Nair, Clegg and Patel, 1986:, Tomblin, Records, Buckwalter, Zhang, Smith, O'Brien, 1997; Shriberg, Tomblin and McSweeny, 1999). A study conducted by (Amayrah and Natour; 2012) reported that the prevalence of communication disorders in Jordanian schools was approximately $15 \%$.

Assessment and treatment of communication disorders is usually conducted by a speech-language pathologist (SLP), who is considered a member of a multidisciplinary team, alongside other health professionals such as physicians, dentists, nurses and professionals in the education field and social services (Glover, McCormack, SmithTamaray ;2015, Yoon, Steele; 2012). Moreover, such collaboration between professions in the evaluation and treatment of communication disorders has an essential impact on overall patient care. (West and Poulton, 1997; Hall , 2005).

The SLP plays a major role in assessment and treatment of different communication disorders, for instance, language and articulation disorders, voice and swallowing disorders, and fluency and resonance disorders (ASHA, 2017). Furthermore, the SLP addresses different age groups, from infants to elderly people, and is employed in a variety of settings such as universities, hospitals, schools, kindergartens and public and private clinics (Plante, Beeson, 2004)

According to the American Dental Association (ADA), the dentist is responsible for general care of teeth and diagnosis and treatment of oral and dental disease in all age groups, including patients with communication disorders, in addition to cooperating with other professionals on the team (ADA, 2017). A number of studies have reported that a qualified dentist should be characterized by a set of features in order to communicate effectively with patients, such as patience, motivation, organizational skill and communication skills, additionally, good listening and understanding of 
the patient's complaint, particularly those of children, because most of them are unable to clearly articulate what or how they feel or respond to questions in connection to describing their pain or symptoms (Armanpreet, ,2014, Lowe, 2013).

Despite the importance of collaboration between the SLP and the dentist, many dentists are less familiar with the role of the SLP in different areas, which leads to either failure to detect the communication disorders or failure to refer to treatment (Vameghi et al., 2015). A study carried out by Crystal and Sullivan (Sultana, 2015) documented that the medical students, which include physicians and dentists, have insufficient knowledge concerning the role of and the services that can be provided by SLPs compared to nurses and occupational and physical therapists. Moreover, a study on Australian public knowledge of the SLP profession documented the awareness of only specific disorders such as stuttering and articulation disorders (Byrne, 2012). A recent study by (Eyndhoven, Chussid and Yoon, 2015) with regards to general knowledge of pediatric dentists about SLP found that despite the fact that the majority of pediatric dentists agreed that speech evaluation should be part of the dental examination, they did not perform well on either the normal speech and language development questions (NSLD), or symptoms of speech and language disorders (SLD), although this information is contained in the Handbook of the American Academy of Pediatrics Dentists (Nowak, Casamassimo, 2011 ).

A study conducted by (Mahmoud, Aljazy and Al Khamrah, 2014) regarding general public knowledge about speech and language pathology (SLPy) in Amman, Jordan, documented insufficient knowledge about communication disorders that are assessed and treated by SLPs, particularly those related to the medical or neurological fields, such as removed larynx $-30 \%$; voice disorders $-37 \%$; cleft lip and palate $-22 \%$; and strokes $-20 \%$.

Generally, people's attitudes are commonly defined as a combination of three aspects - beliefs, feelings and the intention to act. Consequently, there are many elements that vary in a person's attitudes; for instance, working experience, lack of training, limited information and difficulties in communication (Abdulwahab and Al-Gain 2003; Nagarajappa, Tak, Sharda, Asawa, Jalihal, Kakatkar, 2013). A study conducted by ( Sultana 2015) about the attitudes of physicians and dentists in Bangladesh towards SLPs revealed that although the SLP has no separate role in the health professional team, they have a vital role in the assessment and treatment of patients with communication disorders. A number of dentists could name some SLPs; however, some did not have knowledge concerning where this service is being provided.

Despite the fact that SLPy is a developing profession that has only been established in Jordan approximately 20 years ago, to the best of the authors' knowledge, little research has been undertaken to investigate the knowledge and attitudes of Jordanian dentists regarding speech-language pathology. Hence, the purpose of this study is (1) to determine dentists' knowledge about speech-language pathology as a profession and their understanding of the role of SLPs and (2) to evaluate dentists' attitudes regarding SLP.

\section{MATERIALS AND METHODS}

\section{The Questionnaire}

This study was approved by the institutional review board at the University of Jordan. The questionnaire was selfdesigned specifically for the study. A web-based survey program, survey monkey (survey monkey.com, 2007), was chosen to administer the survey and collect the data. The survey was formulated in simple English language and pilot tested using 20 volunteer Jordanian speech-language pathologists and dentists, who were asked to provide feedback on content and clarity. Some comments and suggestions for modifications that were received were incorporated into the final version of the questionnaire. The finalized online survey was distributed via email to all dentists registered with the Jordanian Dental Association Council. Cover letters with a consent form, a link to the survey and an information sheet were enclosed in the email, which stated that participants would be anonymous and their responses would remain confidential.

The questionnaire was divided into four sections: the first section contained six questions (1- 6 items) that collected demographic information of the respondents, comprising age, gender, place of work, academic degree, specialty, and years of work experience.

The second section included 10 items arranged in two categories. Category A (7-11 items) elicited information on the dentists' knowledge about normal speech and language development (NSLD), for example, normal sentence production for a three-year-old child, and the expected age for children to produce sibilant sounds such as (/ s/ and / z /sounds). Category B (12-16 items) elicited information about dentists' knowledge of speech and language disorders (SLD). These items contain scenarios for diverse types of communication disorders, such as language disorders, articulation disorders, voice and swallowing disorders, resonance disorders and fluency disorders, in addition to whether these scenarios should be referred for speech language assessment or not. The response formats for this section included 'true', 'false' and 'I do not know' answers.

The third section (17-23 items) was designed to evaluate the knowledge of the dentists about the speech-language pathologist (SLP) profession; for example, how they first heard about SLP; whether they refer any patients to SLP; and reasons for not referring. Knowledge was assessed about employment settings, ages of clients that SLPs address and the diversity of disorders treated by SLPs, for instance, "people who have had strokes", and situations that do not require an SLP such as "people with pneumonia".

The fourth section required the dentists to rank a number of statements and to provide short answers and was developed to evaluate dentists' attitudes and levels of confidence towards SLPy; for example, whether the SLP is an 
important profession in the rehabilitation team, whether the dentist felt knowledgeable about SLPy or had enough knowledge to explain the SLPy profession to others; and whether they had undertaken a course in communication disorders or could identify some SLP names. This section rated to what degree the respondents agree using a five-point Likert type scale ( $1=$ Strongly Agree, $2=$ Agree, $3=$ Natural, $4=$ Disagree, $5=$ Strongly Disagree). Data were obtained regarding dentists' attitudes towards referral patients with communication disorders to SLPy services as well as reasons for not referring.

\section{Methodology}

The dentists were asked to complete the questionnaire within one month. The completed questionnaires were collected and statistically analyzed with IBM SPSS version 20 software. Pearson Chi- Square was used to identify differences in response for different variables with the level of significance set at p. $>0.05$.

\section{RESULTS}

A total of 235 Jordanian dentists responded to the web-based survey that was distributed to all registered members of the Jordanian Dental Association Council; however, 44 dentists did not answer all the questions, and these were excluded from the study. The final number of respondents was 191 with a response rate of $81 \%$.

\section{A. Demographic Characteristics of the Respondents}

The characteristics of respondents and their practices are shown in Table 1.

TABLE I.

Distribution OF PARTICIPANTS ACCORDING TO DEMOGRAPHIC DATA

\begin{tabular}{|c|c|c|c|}
\hline & & $\mathrm{N}$ & Percentage \\
\hline \multirow[t]{3}{*}{ Gender } & & & \\
\hline & Female & 89 & 46.60 \\
\hline & Male & 102 & 53.40 \\
\hline \multicolumn{4}{|l|}{ Age } \\
\hline & $22-29$ & 104 & 54.45 \\
\hline & $30-39$ & 43 & 22.51 \\
\hline & $40-49$ & 36 & 18.85 \\
\hline & $50+$ & 9 & 4.19 \\
\hline \multicolumn{4}{|l|}{ Practice } \\
\hline & University & $\begin{array}{l}02 \\
45\end{array}$ & 23.56 \\
\hline & Ministry of Health & 19 & 9.95 \\
\hline & Royal Medical Services & 19 & 9.95 \\
\hline & Overseas & 15 & 7.85 \\
\hline & Unemployed & 11 & 5.76 \\
\hline \multicolumn{4}{|l|}{ Dentists } \\
\hline \multirow{10}{*}{ Specialty } & -GDP & 111 & 60.3 \\
\hline & Oral surgeon & 14 & 7.6 \\
\hline & Oral Radiologist & 11 & 4.3 \\
\hline & Oral pathologist & 11 & 3.8 \\
\hline & Orthodontist & 7 & 6.0 \\
\hline & Paedodontist & 8 & 6.0 \\
\hline & Periodontist & 12 & 3.8 \\
\hline & Endodontist & 7 & 1.6 \\
\hline & Fixed and removable Prosthodontist & 3 & 6.5 \\
\hline & Other & 7 & 6.0 \\
\hline \multirow[t]{5}{*}{ Experience } & Less than a year & 47 & 24.6 \\
\hline & 1 year to less than 5 years & 64 & 33.5 \\
\hline & 5 years to less than 10 years & 24 & 12.6 \\
\hline & 10 years to less than 15 years & 25 & 13.1 \\
\hline & 15 years or more & 31 & 16.2 \\
\hline
\end{tabular}

\section{B. Knowledge of Normal Speech and Language Development (NSLD) and Speech and Language Disorders (SLD)}

The number of dentists who correctly answered each statement regarding knowledge of NSLD is shown in Table 2. The number of dentists who correctly answered each scenario about SLD is shown in Table 3. 
TABLE II.

KNOWLEDGE OF NORMAL SPEECH AND LANGUAGE DEVELOPMENT

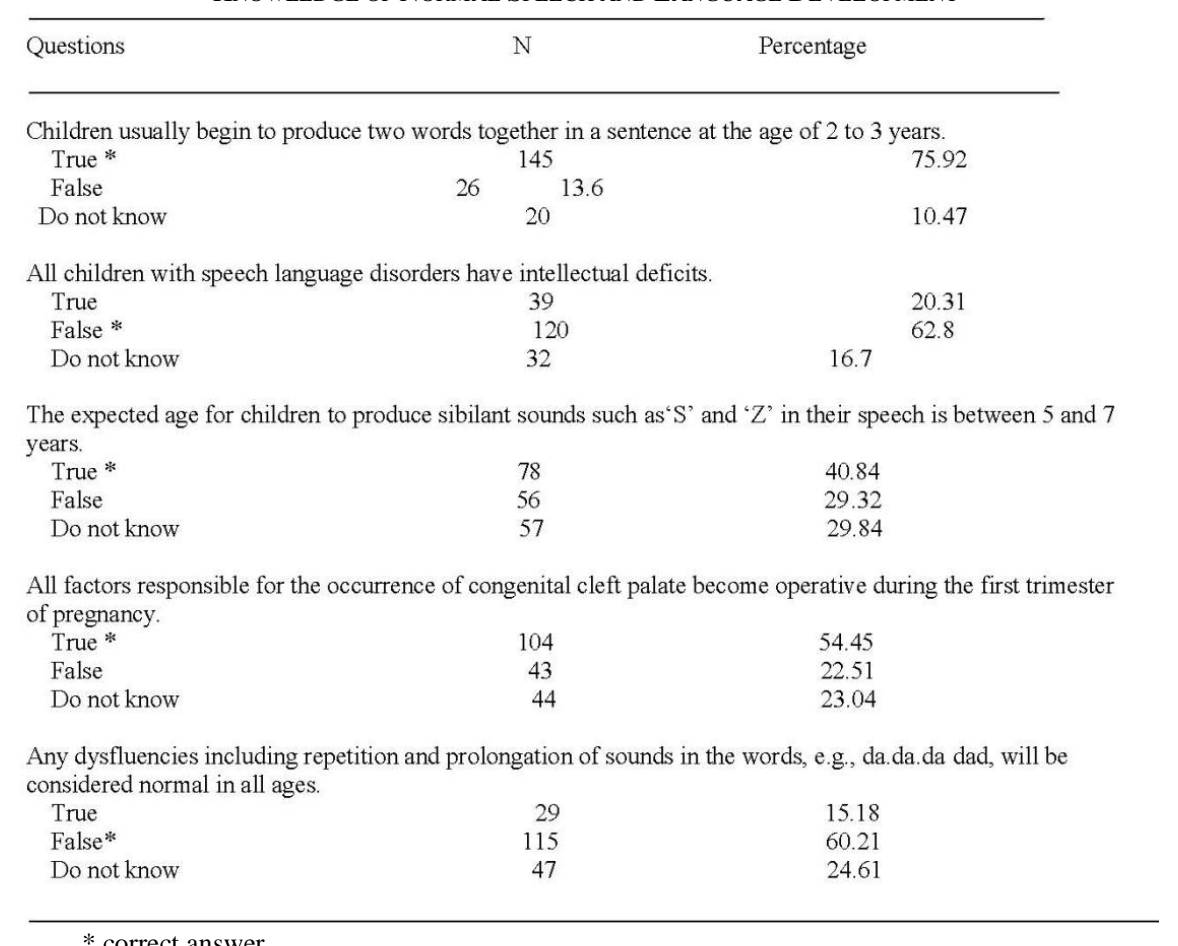

* correct answer

For the NSLD, $26 \%$ of respondents answered four of five statements correctly; only $11 \%$ of the respondents answered all five questions correctly, and 5\% (ten) respondents answered all questions incorrectly.

It was found that $75 \%$ of the respondents $(n=145)$ knew that the expected age for children to produce a sentence that includes two to three words is between two and three years, while $63 \%$ of respondents $(n=120)$ knew that children with SLD were not considered children with intellectual deficits. $40 \%$ of respondents $(n=78)$ believed that the expected age for children to produce sibilant sounds, for example ' $s$ ' and ' $z$ ' sounds, is between five and seven years. More than half of the respondents $54 \%(n=104)$ believed that the factors that led to congenital cleft palate become operative during the first trimester of pregnancy. Finally, $60 \%$ of respondents $(n=115)$ knew that the appearance of dysfluency was not considered normal in all ages.

TABLE III.

KNOWLEDGE OF SPEECH AND LANGUAGE DISORDERS

\begin{tabular}{lcc}
\hline Questions & $\mathrm{N}$ & Percentage \\
In your opinion, if an adult with severe hearing loss wants to learn sign language, he/she should be treated by a \\
speech-language pathologist. & 111 & 58.12 \\
True & 34 & 17.80 \\
False * & 46 & 24.08 \\
Do not know & &
\end{tabular}

Ali, who is 56 years old, suffers from swallowing problems that presented two years ago due to paralysis in his cheeks and tongue muscles. He is currently being treated by a physician, a dentist and a physical therapist; therefore, he does not need to consult a speech language pathologist.

$\begin{array}{lcc}\text { True } & 118 & 62.11 \\ \text { False * } & 41 & 21.58 \\ \text { Do not know } & 31 & 16.32\end{array}$

In your opinion, after laryngectomy (removal of the larynx) there is no need to consult a speech language pathologist.

$\begin{array}{lcc}\text { pathologist. } & 113 & 60.11 \\ \text { True * } & 40 & 21.28 \\ \text { False * } & 35 & 18.62 \\ \text { Do not know } & & \end{array}$

Do not know 35

Hoarseness, decreased pitch range, and neck pain are symptoms of voice disorders.

$\begin{array}{lcc}\text { True * } & 84 & 43.98 \\ \text { False } & 33 & 17.28 \\ \text { Do not know } & 74 & 38.74\end{array}$

In your opinion, a three-year-old child who has a repaired cleft palate with several dental anomalies should consult a speech-language pathologist.
True *
False
Do not know
142
$28^{21}$

* correct answer 
To test their knowledge about SLD, respondents were asked to make judgments on five different SLD scenarios: $18 \%$ of respondents answered four of five scenarios correctly, while $5 \%$ of respondents answered all five scenarios correctly; however $13 \%$ of respondents answered all questions incorrectly. A high percentage of respondents $(58 \%)(\mathrm{n}=$ 111) reported that the SLP was considered the best professional for teaching sign language to deaf or hard-of-hearing people. Interestingly, $62 \%$ of respondents $(n=118)$ were unaware that patients with swallowing disorders should be referred to an SLP as well as other professionals. Moreover, $60 \%$ of respondents $(n=113)$ also believed that there was no need to consult an SLP after laryngectomy (larynx removed). In addition, 43\% of respondents ( $\mathrm{n}=84) \mathrm{knew}$ the main symptoms of voice disorders, and $75 \%(n=142)$ believed that children who had cleft palatal repair have SLD and must be evaluated and treated by an SLP.

There was no statistically significant difference in age, gender, year of practice, place of practice and specialty of dentists for knowledge of NSLD and SLD.

\section{Knowledge about the Speech-language Pathologist (SLP)}

For all dentists questioned, 62\% $(n=120)$ had heard about the SLP, and 51\% $(n=98)$ of them reported that they gave advice to consult an SLP, while only $29 \%(n=55)$ of respondents actually referred their patients for speech-language assessment. The respondents had many different reasons for not referring a patient with SLD to an SLP; approximately $68 \%$ of dentists had a lack of knowledge about SLPs, and half of dentists had a lack of knowledge of referral procedures. Additionally, $43 \%$ of respondents were uncertain about the diagnosis, and over a quarter of respondents, $26 \%$, reported that parents may become angry about a referral to an SLP. The dentists' reasons for not referring patients to speech and language clinics are listed in Table 4.

TABLE IV.

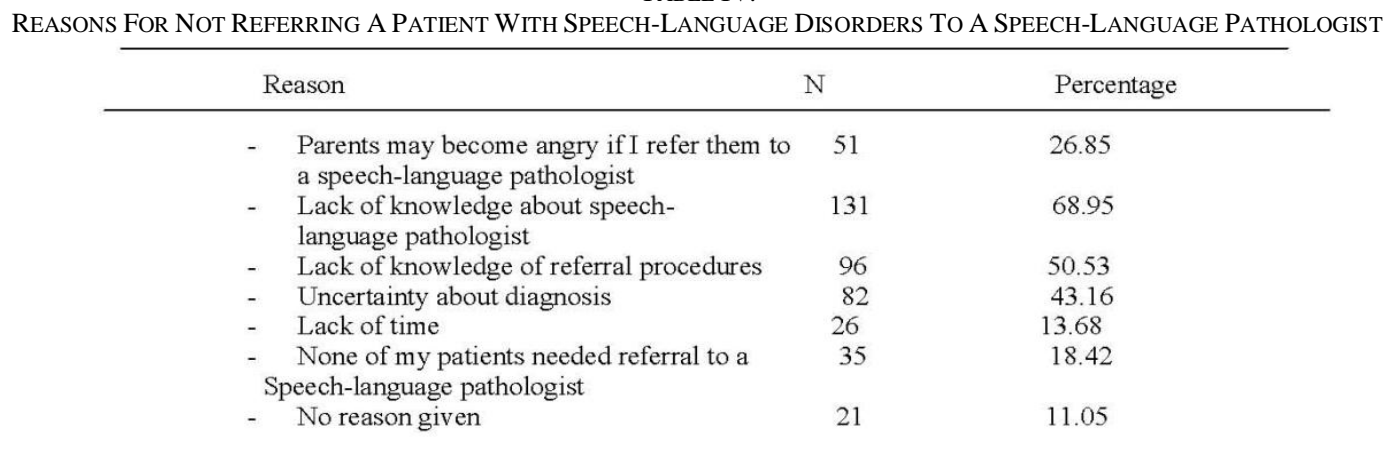

Half of the respondents, $51 \%$, obtained information about SLPs from work experience, $41 \%$ from university curricula, $28 \%$ from reading, $23 \%$ from the internet, and $16 \%$ from a friend. For the group of ages that SLPs address, the highest percentages were $83 \%$ for grade school children, $80 \%$ for teenagers, $77 \%$ for preschool children, and $65 \%$ for adults, while the lowest percentages were $41 \%$ for elderly people and $26 \%$ for infants. Interestingly, just $16 \%$ of all respondents agreed that SLP worked with all age groups listed above.

Concerning places where SLPs are employed, almost three quarters, 74\%, of respondents reported that SLPs are employed in private clinics, $63 \%$ in hospitals, $58 \%$ in schools, $46 \%$ in universities, and $41 \%$ in kindergartens. Unfortunately, $12 \%$ of respondents believed that SLPs worked in all the above settings. Finally, the respondents were asked to determine whether an SLP is typically involved in treating different disorders or not.

Notably, the dentists cannot differentiate between the situations that do require an SLP, for example, people with cleft palate, and those that did not require an SLP, for example, people with muscle disease. The results indicated that the dentists have a good knowledge of "people with cleft palate" and "children who are late to talk," with the percentages of $83 \%$ and $82 \%$, respectively. The percentages of respondents according to the diversity of disorders treated by SLP are shown in Table 5. 
TABLE V.

DENTISTS’ RESPONSES By PERCENTAGE REGARDING DIVERSITY OF DisORDERS TREATED By SLP

\begin{tabular}{lcc}
\hline Type of Disorders & N & Percentage \\
\hline People with diseases or injuries of the brain & 110 & 57.59 \\
People with fluency disorders, e.g., stuttering & 141 & 73.83 \\
People with hearing loss & 147 & 76.96 \\
Children with autism & 135 & 70.6 \\
People with pneumonia & 10 & 5.2 \\
People with voice disorders & 73 & 38.53 \\
People who have had strokes & 56 & 29.7 \\
People who lose their eyesight & 44 & 17.28 \\
People with cleft palate & 159 & 83.25 \\
People with mental retardation & 81 & 42.41 \\
People with leukemia & 6 & 3.1 \\
People with tonsillitis & 11 & 5.76 \\
People with swallowing disorders & 65 & 34.03 \\
People with dementia or memory deficit & 32 & 16.75 \\
People with muscle diseases & 77 & 40.3 \\
People who start talking late & 158 & 82.72 \\
\hline
\end{tabular}

There was no significant difference between variable factors in this study and dentists' knowledge related to SLP.

\section{Attitudes towards Speech and Language Pathology (SLPy)}

In this section, there were a few questions that had to be answered on a scale from 1 to 5 (1= strongly agree and $5=$ strongly disagree). We found no significant differences between different variables related to age, gender, place of work, academic degree, and years of work experience and attitudes towards SLPy. Most of the dentists - 86\% - agreed or strongly agreed that SLPy is a vital profession in the rehabilitation healthcare team. Although $40 \%$ of dentists agreed or strongly agreed that they feel knowledgeable about SLPy, 71\% of dentists disagreed or strongly disagreed that they have enough knowledge to explain SLPy to other professionals. Moreover, 39\% of dentists agreed or strongly agreed that they can confidently recognize signs of SLD in the clinical setting, and $82 \%$ of dentists agreed or strongly agreed that they are willing to attend a continuing education course in SLD. Dentists' attitudes toward speech-language pathology (SLPy) are listed in Table 6.

TABLE VI.

DENTISTS’ ATtitudes TOWARD SPEECH-LANGUAGE PATHOLOGY (SLPY)

\begin{tabular}{|c|c|c|c|}
\hline Statement & $\begin{array}{l}\text { Percentage of agree or } \\
\text { strongly agree }\end{array}$ & Neutral & $\begin{array}{l}\text { Percentage of disagree or } \\
\text { strongly disagree }\end{array}$ \\
\hline $\begin{array}{l}\text { 1. Speech language pathology is a vital profession in the } \\
\text { rehabilitation healthcare team }\end{array}$ & $86.9 \%$ & 10.99 & 2.1 \\
\hline 2. I feel knowledgeable about speech-language pathology & 39.27 & 32.46 & 28.27 \\
\hline $\begin{array}{l}\text { 3. I feel I have enough knowledge to explain speech- } \\
\text { language pathology to other professionals }\end{array}$ & 25.13 & 23.56 & 51.35 \\
\hline $\begin{array}{l}\text { 4. I can confidently recognize signs of speech language } \\
\text { disorders in the clinical setting }\end{array}$ & 39.79 & 31.94 & 28.27 \\
\hline $\begin{array}{l}\text { 5. I am aware of specialized centers for speech-language } \\
\text { disorders in Jordan }\end{array}$ & 32.07 & 20.11 & 47.83 \\
\hline $\begin{array}{l}\text { 6. I know the name of at least one speech-language } \\
\text { pathologist who works in Jordan }\end{array}$ & 29.29 & 12.57 & 58.65 \\
\hline $\begin{array}{l}\text { 7. I had a course in communication disorders or speech } \\
\text { language disorders at the university }\end{array}$ & 47.28 & 11.05 & 41.67 \\
\hline
\end{tabular}

\section{DISCUSSION}

This cross-sectional study was conducted to investigate the knowledge of Jordanian dentists regarding the speechlanguage pathologist's roles. There is a lack of published studies on dentists' knowledge about SLPy as well as about NSLD and SLD; to the best of our knowledge, little research has been undertaken in Jordan.

In the present study, the majority of respondents had a low level of knowledge about NSLD, which agrees with the study conducted by (Eyndhoven et al, 2015). In that study, less than $1 \%$ of respondents answered all statements correctly for NSLD even though those normal milestones are listed in the American Academy of Pediatric Dentistry (AAPD) handbook. Moreover, the highest percentage of dentists' knowledge about NSLD was 75\% for normal language development, while the lowest percentage for NSLD was $40 \%$ for articulation development. A possible explanation for this high percentage is the type of communication between dentists and children, which depends on oneto-one interaction. In other words, children typically can respond to dentists' questions about pain depending on their age and based on how much they have developed language to express their feelings. This communication may appear simple if the child can produce clear and organized sentences, which makes judgment on his/her language development by dentists easy and uncomplicated. Otherwise, the lowest percentage is associated with the articulation disorders, which are defined as "an inability to produce certain speech sounds" (Bauman, 2012). 
In other words, this result depends on dentists' general understanding of the child's intelligibility of sounds; usually, the dentist pays more attention to the general context of speech instead of appropriate and correct production of each sound.

In terms of dentists' knowledge about SLD, the respondents were asked to make decisions on different scenarios about SLD and whether these are needed for referral to an SLP. With regards to the first scenario, 58\% of respondents believed that one of the responsibilities of the SLP is to teach sign language for deaf or hard-of-hearing people. Moreover, the deaf community is defined as those individuals who use signed language as their primary mode of communication. For decades, confusion has existed over the differences in the roles of the SLP and a sign language assistant/interpreter, who is responsible for helping deaf or hard of hearing individuals understand what is being said in a variety of situations. However, despite the importance of collaborative work between all team members to help deaf or hard-of-hearing people, no specific policy could be found regarding the diagnosis or treatment of individuals who are deaf or hard of Hearing in ASHA's publication. Otherwise, ASHA and the Council on Education of Deaf and National Association of Deaf reported that a signed language assistant/interpreter must be certified by the National Association of the Deaf in sign language or hold a specialized certificate or degree program in American Sign Language interpretation, regardless of whether they already hold a Bachelor's or Master's degree in SLPy (Cripps, Cooper, Supalla and Evitts, 2016).

Regarding the second, third and fourth scenarios, we found that respondents' awareness related to these disorders that have neurological bases according to the ASHA classification is limited: a high percentage of dentists $-60 \%$ and $67 \%$, respectively - agreed that there was no need for an SLP to treat swallowing disorders or laryngectomees, which is similar to a previous study (Byrne, 2010). Recently, a study conducted by (Mahmoud, AL Jazi and ALkhamrah ,2014) reported inadequate public knowledge of some SLDs, for example, swallowing disorders, voice disorders and following strokes; however, there are several reasons why this may be the case. First, the general idea among the public as well as among the respondents in this study is that SLPs are needed in cases that directly involve language and speech problems such as language disorders, articulation disorders, and stuttering, and that there is no important role for SLPs in medical or neurological disorders. Second, many patients with medical problems, for example, body and head injuries, strokes and laryngectomy, visit the medical profession initially for evaluation, for example, physicians, dentists and Otolaryngologists, and those key members in the medical field are unaware of the services an SLP can provide patients. Therefore, a big gap exists between medical professions and SLPs due to the very limited exposure to the field of SLPy. Finally, a lack of SLPy clinics in Jordanian hospitals has led to a decrease in the interaction between all team members in addition to reducing the appropriate procedures of referral.

In contrast, $75 \%$ of respondents in the final scenario agreed that patients with cleft lip and palate must be evaluated and treated by SLPs, and this high percentage of knowledge suggests that dentists were more familiar with cleft palate cases; moreover, dentists had the topic of cleft palate included in their university curriculum, as well as clinical exposure to individuals with cleft palate.

The respondents for the present study exhibit no significant difference between ages, gender, years of practice, place of practice and specialty of dentists and knowledge of NSLD and SLD. These results indicate that a need for general awareness of normal and abnormal milestones in the field of SLPy.

Although approximately two-thirds of the dentists in this study had some knowledge about SLPs and half of them reported that they gave advice to consult SLPs, most of the dentists did not refer their patients to speech and language clinics. The main reasons for Jordanian dentists not to refer patients with SLD were lack of knowledge about SLPy, uncertainty about referral procedures, uncertainty about diagnosis, and fear of anger from parents. All these responses led to a result that focused on the value of educating dentists and increasing their knowledge of normal milestones of speech and language as well as SLD so they can detect and refer such cases. These findings are consistent with the results of (Vameghi et al. 2015) who reported that insufficient knowledge of professionals meant that children with SLD were not detected, or were not referred for SLPs.

An unexpected result of the current investigation was that under half of the dentists - $41 \%$-acquired their information about SLPs from work experience, then from the university curriculum. This is a low percentage, which suggests a lack of adequate information conveyed in academic programs, which raises the importance of effective education with specific courses related to NSLD and SLD to increase the dentists' knowledge and awareness. On the other hand, the results showed that work experience is the initial and most vital information resource; a good explanation for this is that dentists communicate directly with patients in the dentistry clinic and this kind of communication opens up more opportunities to exchange information with others in the work place and seek the appropriate professional.

Another finding was that dentists little knowledge of SLP presented by the little awareness of places that employed SLPs and the age groups that SLPs address. The results clearly revealed that even though a large number of dentists believed that the private clinics were the initial institutions that employed SLPs, followed by schools, universities, hospitals and kindergartens, only $12 \%$ of dentists thought that SLPs work in all five places. Furthermore, with regards to age groups that SLPs address, the results illustrated that a high percentage is recorded for school-age children and teenagers, with a low percentage recorded for infants and elderly people. There are some reasons for these results: first, according to the American Academy of Pediatric Dentistry, children's first dental visit must be scheduled at the first 
birthday. However, a study conducted by ( Draidi, AL-Olaimat, Hyasat, Othman and Sakarna ,2014) suggested that the age range on the first dental visit in Jordanian children was 24-144 months; thus, dentists' knowledge about this group under two years of age is limited due to rare appointments between those children and the dentist. Second, regarding elderly people, we found that many dentists have no information about the role of SLPs with elderly people, for example, whether SLPs provide vital services to those individuals who do have communication, cognitive, or swallowing impairments following illness, trauma, or disease. In addition, there is a lack of knowledge on how to prevent communication and swallowing disorders by promoting a healthy lifestyle and educating consumers about how to prevent strokes and other disorders that may lead to speech and language impairments.

With regard to cases that SLPs work with, we found that the dentists were able to make judgment on language delay, cleft lip and palate, and stuttering, while voice disorders, swallowing disorders and hearing loss were the most difficult to distinguish. Once again, there is a need to raise the awareness of dentists regarding the disorders that SLPs can become involved in to ensure that these unrecognized disorders will be identified in the first instance and that patients are referred and receive effective treatment.

Finally, regarding dentists' attitudes toward SLP, the overall responses in this sample agreed that SLPy is a vital profession on a healthy team; however, the majority of the respondents indicated that they were not knowledgeable enough about SLPy as a profession to explain SLPy to other professionals. Moreover, $70 \%$ of the dentists reported that they had not attended a specialized course in SLD at the University of Jordan and were unconfident in their ability to recognize the signs and symptoms of SLD. Over $80 \%$ of respondents stated they are willing to attend a continuing course in SLD. The results of this survey suggest that dentists need more extensive and effective education to increase their knowledge and awareness of all aspects of NSLD as well as SLD.

\section{CONCLUSION}

This study showed insufficient knowledge of dentist regarding normal speech-language development and speechlanguage disorders. In addition, the majority of respondents agreed that SLPy is a vital profession in the rehabilitation healthcare team. The main reasons for dentists not referral patients with communication disorders for speech language pathologist included lack of knowledge about SLP and referral procedures.

\section{REFERENCES}

[1] Abdulwahab, S., \& Al-Gain.S. (2003). 'Attitudes of Saudi Arabian health care professionals towards people with physical disabilities'. Asia Pacific Disability Rehabilitation Journal, Vol, 14(1) 63-70

[2] Amayreh, M., \& Natour.Y. (2012). Introduction to Communication Disorders ( $1^{\text {ST ed) }}$ Jordan: Daralfijer

[3] American Speech-Language-Hearing Association. (2017). Clinical supervision in speech-language pathology [position statement]. http://www.asha.org/policy/RP1993-00208/ [Retrieved on 22 November, 2017]

[4] American Academy of dentistry. (2017). Glossary of Dental Clinical and Administrative Terms: http: //www.ada.org/en/publications/cdt/glossary-of-dental-clinical-and-administrative-ter. [Retrieved on 22 November, 2017]

[5] Armanpreet, K. (2014). 'Communication amongst Dentists, Patients, and Parents - A Triad'. UC Merced Undergraduate Research Journal, 7 (2) 58- 67

[6] Beitchman, JH., Nair , R., Clegg, M., Patel, P.G.(1986).'Prevalence of speech and language disorders in 5-year-old kindergarten children in the Ottawa-Carleton region. Journal of Speech and Hearing Disorders. 1986; 51(2):98-110.

[7] Bauman, J. (2012). Articulation and phonological impairments, a clinical focus, $4^{\text {th }}$ edition. New Jersey: Pearson Education

[8] Byrne, N. (2010). 'Why do students from related professions choose not to enter speech language pathology? 'International Journal of Speech-Language Pathology, 12(4): 344-351.

[9] Cripps, J., Sheryl C., Samuel S., \& Paul, E. (2016). 'Meeting the needs of signers in the field of speech and language pathology: Some considerations for action'. Communication Disorders Quarterly, 37(2), 108-116.

[10] Draidi, Y., AL- Olaimat, A., Hyasat, A., Otman, E., \& Al- Sakarna, B. (2014).' The most common chief complaint among Jordanian children at first dental visit'. Pakistan Oral \& Dental Journal Vol 34, (2), 330-334

[11] Eyndhoven, L., Steven C., \& Yoon, R. (2015). 'Knowledge, Attitudes, and Practices of Pediatric Dentists Regarding Speech Evaluation of Patients: Implications for Dental Education', Journal of Dental Education, Vol 79(11):1279-85

[12] Glover, A., McCormack, J., \& Tamaray, M. (2015). 'Collaboration between teachers and speech and language therapists: Services for primary school children with speech, language and communication needs'. Journal of child language Teaching and therapy Vol.31 (3) 363- 382

[13] Hall, P. (2005). 'Interprofessional teamwork: Professional cultures as barriers.' Journal of Interprofessional Care Vol19. (1) $188-196$.

[14] Lowe, O. (2013). 'Communicating with parents and children in the dental office'. Journal of the California Dental Association, 41(8), 597- 601.

[15] Mahmoud, H., Al- jazy, A., \& Al- khamrah, R. (2014). 'A study of public awareness of speech language pathology in Amman', College Student Journal, Vol 48(3), 495-507

[16] McLaughlin, S. (2007). Introduction to language development. University of Central Oklahoma:Clifton Park, NY: Thomson Delmar Learning.

[17] Nagarajappa, R., Tak, M., Sharda, AJ., Asawa, K., Jalihal S., \& Kakatkar G. (2013).' Dentists' attitudes to provision of care for people with learning disabilities in Udaipur, India'. Scandinavian Journal of Caring Sciences. 27(1):57-62. 
[18] Nowak, A. \& Casamassimo, P., (2011). American Academy of Pediatric Dentistry handbook of pediatric dentistry. 4th ed. Chicago: American Academy of Pediatric Dentistry

[19] Plante, E., \& Beeson, P. (2004). Communication and communication disorders; a clinical introduction, Pearson education, Inc

[20] Shriberg, L., Tomblin, J., \& McSweeny, J. (1999) 'Prevalence of speech delay in 6-year-old children and comorbidity with language impairment'. Journal of Speech, Language, and Hearing Research. 42(6):1461-81.

[21] Sultana, R. (2015). 'Physician's perception about the role of speech and language therapy', Unpublished thesis B.S. Bangladesh Health Professions Institute. (BHPI) Chapain, Savar, Dhaka-

[22] Tomblin , J., Records, N., Buckwalter, P., Zhang, X., Smith , E., \& O'Brien .M. (1997). Prevalence of specific language impairment in kindergarten children. Journal of Speech, Language, and Hearing Research; 40(6):1245-60.

[23] Vameghi, R., Bakhtari, M., Shirinbayan P., \& Hatamizadeh. N. (2015). Delayed Referral in Children with Speech and Language Disorders for Rehabilitation Services, Iranian rehabilitation journal, Vol. 13(1): 16-21

[24] Van Hatturn, R. (1985b). Organization of speech-language services in schools: A manual. San Diego: CA: College-Hill Press.

[25] West, P. (1997). A failure of function: Teamwork in primary health care. Journal of Interprofessional Care 1 1: 2, $205-216$.

[26] World Health Organization. (2017). Disability and health, http://www.who.int/mediacentre/factsheets/fs352/en/. [Retrieved on 10 November, 2017].

[27] Yoon, M N., \& Steele, C. (2012). Health care professionals' perspectives on oral care for long-term care residents: nursing staff, speech-language pathologists and dental hygienists. Gerodontology Journal .29(2):e525

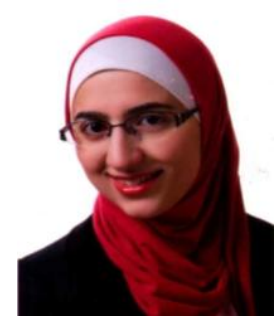

Hana Nawaf Mahmoud is an instructor at the Department of Hearing and Speech Sciences at The University of Jordan. She obtained her Master degree in Speech and Language Pathology from The University of Jourdan in 2003.

Mahmoud has over 15 years of experience as a clinical supervisor and as a speech and language pathologist for both children and adults in a number of settings include public and private schools, rehabilitation centers, and university clinics.

Mahmoud's experience includes working with individuals with Developmental Delays, Apraxia, Fluency Disorders, Learning Disabilities, Intellectual Disabilities, Down Syndrome, Cerebral Palsy, Hearing Impairments, Expressive/Receptive Language Impairments, Articulation/Phonology Disorders, Voice disorders.

Mrs. Mahmoud is licensed in Speech Pathologist Profession, by Ministry of Health, Amman - Jordan.

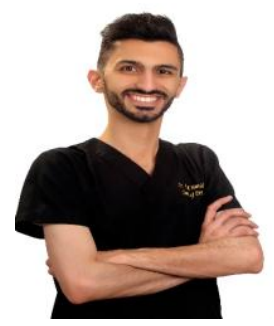

Abdelhameed N. Mahmoud graduated as a Doctor of Dental Surgery (DDS) from the Dental school affiliated with The University of Jordan (2013), Amman, Jordan

He has a Six-year working experience, has worked as a General Practioner Dentist at the Jasmin Dental Implant Center in Amman, Jordan (Since 2015-till now). He worked as INTERN DENTIST for a year period (July,2014-July,2015) conducted at the Jordanian Ministry of Health

Dr. Mahmoud Participated in a national campaign providing measles, rubella and polio vaccinations, as well as vitamin A supplements, to protect all communities in Nov. $5^{\text {th }} 2013$. Also Dr. Mahmoud is a member of Oral Health Education Committee (OHEC). He has been working as a co-author among the research team investigating and working on the development and design of novel gold nanoparticles as antibacterial agents for dental applications in The University of Jordan and AL-Zaytona University of Jordan. 